\title{
Drug-Related Adverse Events: description of an active search process in a teaching hospital of the Sentinela Network
}

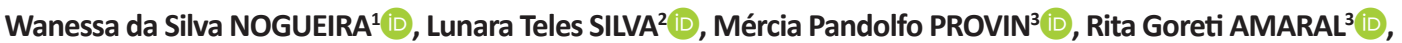 \\ Tatyana Matteucci FERREIRA ${ }^{4}$ id, Ana Carolina MODESTO ${ }^{4}$ iD \\ ${ }^{1}$ Residência Multiprofissional em Saúde Hospital das Clínicas-Universidade Federal de Goiás; ${ }^{2}$ Programa de Pós-Graduação em Ciências da Saúde, \\ Faculdade de Medicina-UFG; ${ }^{3}$ Faculdade de Farmácia-Universidade Federal de Goiás; ${ }^{4}$ Hospital das Clínicas-Universidade Federal de Goiás \\ Corresponding author: Modesto AC, farmcarolina@gmail.com
}

Submitted: 20-02-2021 Resubmitted: 14-03-2021 Accepted: 15-03-2021

Peer review: Suelem Tavares da Silva-Penteado, Daniela Archanjo and Jôseffer Wianey Trindade-Medeiros

\begin{abstract}
Objective: To describe the implementation of an active search service for adverse drug events (ADE) in a teaching hospital in the Midwest region of Brazil. Method: Observational sectional study conducted at the Pharmacovigilance Service in a University hospital in the Midwest Region of Brazil, from March to August/2019. All patients admitted to a medical clinic unit were included and those who did not find medical records were excluded. A work process structured in six stages was elaborated: 1) elaboration of a list of triggers through literature review; 2 ) elaboration of a list of patients whose previously selected triggers appeared; 3) visiting the wards and reviewing medical records; 4) validation of ADE; 5) notification of ADE to Agência Nacional de Vigilância Sanitária; 6) registration of information in databases. Results: The Positive Predictive Value (PPV) of each trigger was calculated individually and globally. The relative and absolute frequency of ADE was calculated as to the type, description and the drug involved. A total of 479 searches were made in the period and the frequency of ADE was $7.48 \%$. The global triggers PPV was 0.04. The trigger with the best performance was promethazine (1.00), followed by the Activated Partial Thromboplastin Time (0.67). Regarding the identified ADE, it was observed that most of the time, $24.14 \%$ were related to infusion reactions. It was observed that $53.85 \%$ of the drugs involved in ADE were high alert medications. Conclusion: It was observed that the implementation of an active search service for ADE in hospitals that do not have the support of an electronic medical record system is feasible to be performed. It was also observed a high frequency of ADE and that the active search guided by triggers allows to identify events that otherwise could not be identified.
\end{abstract}

Keywords: pharmacovigilance; drug-related side effects and adverse reactions; medication errors; patient safety; pharmacy service, hospital; risk management.

\section{Eventos Adversos a Medicamentos: descrição de um processo de busca ativa em um hospital de ensino da Rede Sentinela}

\section{Resumo}

Objetivo: descrever a implantação de um serviço de busca ativa de eventos adversos (EAM) em um hospital de ensino da região CentroOeste do Brasil. Método: estudo observacional seccional realizado no Serviço de Farmacovigilância em um hospital Universitário da Região Centro-Oeste do Brasil, no período de março a agosto/2019. Foram incluídos todos os pacientes internados em uma unidade de clínica médica e excluídos aqueles que não foram encontrados os prontuários. Foi elaborado um processo de trabalho estruturado em seis etapas: 1) elaboração de uma lista de rastreadores por meio de revisão de literatura; 2) elaboração de uma lista de pacientes cujos rastreadores previamente selecionados apareceram; 3) visita às enfermarias e revisão de prontuário; 4) validação do EAM; 5) notificação dos EAM para a Agência Nacional de Vigilância Sanitária; 6) registro das informações em bancos de dados. Foi calculado - Valor Preditivo Positivo (VPP) de cada rastreador individual e globalmente. Foi calculada a frequência relativa e absoluta dos EAM quanto ao tipo, descrição e o medicamento envolvido. Resultados: foram feitas 479 buscas no período e a frequência de EAM foi de 7.23\%. O VPP global dos rastreadores foi de 0.04 . O rastreador que apresentou a melhor performance foi a prometazina (1.00), seguido do Tempo de Tromboplastina Parcial Ativada (0.67). Em relação aos EAM identificados, observou-se que a maioria das vezes, $24.14 \%$ estiveram relacionados a reações infusionais. Verificou-se que $53.85 \%$ dos medicamentos envolvidos nos EAM eram de alta vigilância. Conclusão: Evidencio-se que a implantação de um serviço de busca ativa de EAM em hospitais que não contam com o apoio de sistema de prontuário eletrônico é factível de ser executada. Observou-se ainda uma alta frequência de EAM e que a busca ativa orientada por rastreadores permite identificar eventos que de outra maneira não poderiam ser identificados.

Palavras-chave: farmacovigilância; efeitos colaterais e reações adversas relacionados a medicamentos; erros de medicação; segurança do paciente; serviço de farmácia hospitalar; gestão de riscos. 


\section{Introduction}

Approximately $6 \%$ of the hospitalized patients are subjected to some type of Drug-Related Adverse Event (DRAE); more than 700,000 emergency room visits and 120,000 hospitalizations are caused by DRAEs in the United States alone. ${ }^{1}$ It is estimated that nearly $1 \%$ of the world health budget is spent on treating the harms associated with medication use. ${ }^{2}$ In this context, DRAEs have emerged in recent years as a public health problem and have been on the global health agenda as a priority since 2017 with the publication of the "Third WHO Global Patient Safety Challenge: Medication without Harms", whose objective is to reduce by $50 \%$ the severe and avoidable harms related to medication use worldwide, until $2022 .^{2}$

This global challenge can be even more challenging for Brazil, since the assessment of DRAEs in the country is still incipient, as identified in a systematic review of DRAEs in hospitals, where it was shown that only $6.9 \%(n=2)$ of the studies retrieved were conducted in Brazil. ${ }^{3}$ To attain the goal proposed by the World Health Organization (WHO), it is first necessary to know the frequency of DRAEs to assess the increase or reduction in harms over time.

Nearly $95 \%$ of the DRAEs are not informed through Spontaneous Notification (SN) by the health professionals, either for fear of suffering penalties or even due to shame. ${ }^{4} \mathrm{~A}$ study carried out in a Brazilian public institution showed that, among 356 DRAEs, only one was notified by health professionals. ${ }^{5}$ Underreporting of DRAEs is a problem faced by several countries in the world and can compromise the implementation of measures to promote safety in the use of medications. ${ }^{6}$

Another method for the identification of DRAEs could be used by the health institutions. ${ }^{5}$ The conventional active search (AS) for DRAEs consists of reviewing medical records both retrospectively and prospectively to identify potential incidents. ${ }^{7}$ Although it presents better results when compared to the $\mathrm{SN}$, this method still has the major disadvantage of being time-consuming and expensive, in addition to presenting great variability of results between different evaluators. ${ }^{7}$

The need to use more efficient methods for detecting DRAEs has emerged since the 1970s, but it was only in 2003 that this gap was filled when a group of researchers proposed a method of AS for DRAEs guided by triggers, which consists of the search for evidence of potential harms caused by the use of medications by means of clues recorded in the patient's medical record.? Examples of these clues are the use of specific antidotes, such as the administration of naloxone to reverse the effects of excessive sedation by the use of opioids ${ }^{8}$, or vitamin $\mathrm{K}$ to reverse the excessive anticoagulation caused by coumarin agents. ${ }^{9}$ Other indications of DRAEs are the results of laboratory tests, such as elevated creatinine, which can indicate possible druginduced nephrotoxicity, ${ }_{10}^{10}$ as well as the use of antihistamines for the treatment of drug-induced skin rash. ${ }^{11}$

Trigger-guided AS has been improved and validated by the Institute of Healthcare Improvement (IHI) in a tool for the AS of DRAEs. ${ }^{12}$ Diverse evidence suggests that this method is capable of identifying ten times more DRAEs when compared to conventional AS and SN. ${ }^{13}$ In Brazil, studies using the AS method guided by triggers are still scarce; however, surveys conducted in university hospitals in the states of Rio de Janeiro, ${ }^{10}$ São Paulo $^{5}$ and Amazonas ${ }^{9}$ showed that it optimizes the time of the team of researchers and does not demand large investments, in addition to being able to identify DRAEs that could not be identified by other methods.

Considering the importance of safety in the use of medications in the global health agenda, this study aims to describe the implementation of an AS process for DRAEs through triggers in order to contribute to the generation of evidence that promotes patient safety.

\section{Methods}

This is a cross-sectional and observational study. It was carried out in the Pharmacovigilance Service (PVS) of the Risk Management Unit (RMU) of the Quality Management and Health Surveillance Sector, hierarchically linked to the Health Care Management of the Clinical Hospital of the Federal University of Goiás/Brazilian Company of Hospital Services (Hospital das Clínicas da Universidade Federal de Goiás-Empresa Brasileira de Serviços Hospitalares, HC-UFG/EBSERH). The PVS was incorporated into the RMU organization chart in February 2017 and has a staff composed of two pharmacists with an exclusive dedication of 30 hours a week each and students of the Multidisciplinary Residency in Health Course, according to availability of rotation.

The data were obtained through documentary research in the physical files (standard operating procedures, forms, flows) and electronic spreadsheets of the PVS and refer to the period from March $1^{\text {st }}, 2019$ to August 31 $31^{\text {st }}, 2019$. The study population consisted of all patients hospitalized in the inpatient unit of the medical clinic who had at least one trigger identified, and those whose medical records were not found during the search were excluded. The stages for the implementation of the active search service are described in Figure 1.

In the referred period, the AS occurred in an inpatient unit of a 60-bed Medical Clinic, which provides care to patients in numerous specialties: hematology, pneumology, cardiology, gastroenterology and neurology. This inpatient unit was selected to start the implantation of the AS guided by triggers because it is a 60 -bed ward with patients from different medical specialties.

The AS was conducted according to what is proposed by the IHI. ${ }^{14}$ The DRAEs were classified as follows: Adverse Drug Reaction (ADR); Technical Complaint; Therapeutic Ineffectiveness; Offlabel use; and Medication Error (ME). ${ }^{15}$ The medications in use were classified according to the Anatomical Therapeutic Chemical Classification. ${ }^{16}$ High-alert medications (HAM) were classified according to the Institute of Safe Practices for the Use of Medications in Brazil. ${ }^{17}$

The frequency of DRAEs was calculated dividing the number of DRAEs identified by the total number of searches conducted in the period. The Positive Predictive Value (PPV) was calculated for each trigger. The PPV was calculated by dividing the number of times a trigger was able to identify a DRAE by the total number of times the trigger was present. ${ }^{18}$ The data were processed and analyzed using the Epi Info, version 7.2, STATA 14.0 and Microsoft Excel $^{\circledR}$ software programs. Descriptive statistical analysis was performed with estimations of relative and absolute frequencies. 
This study was conducted according to the ethical precepts set forth in Resolution 466/2012 and approved by the Research Ethics Committee of HC-UFG/EBSERH, with CAAE Protocol No.: 26902719.7.0000.5078.

\section{Results}

The implementation of the AS for DRAEs resulted in a six-stage process which is described in detail in Figure 2. The triggers used in the AS are described in detail in Table 1.

A total of 479 searches were conducted in the period, and in $16.28 \%(n=78 / 479)$ of the cases, the medical records were not found, resulting in $83.72 \%(n=401 / 479)$ of valid searches. The frequency of DRAEs was $7.48 \%(n=30)(95 \% \mathrm{Cl}=4.80-10.0)$. The overall PPV of the tool was 0.04 . The triggers that showed the best performance were promethazine and serum potassium $>6$ $\mathrm{mg} / \mathrm{dL}$, with values of 1.00 for both. The second trigger with the best performance was the International Normalized Ratio, with a value of 0.67

Regarding the classification of the DRAEs, there was a higher frequency of ADRs $(62.07 \% ; n=19)$ when compared to MEs (37.93\%; $\mathrm{n}=11)$. In relation to the characteristics of the DRAEs identified, the results are described in Table 2. It was found that, in $23.33 \%(n=7)$ of the cases, DRAEs were related to infusion reactions. Among the DRAEs involving the infusion of medications, the presence of fever, chills, dyspnea and desaturation during the infusion of amphotericin B occurred in $28.60 \%(n=2)$ of the cases. Severe sweating and burning sensation in the body during intravenous potassium chloride infusion also occurred in $28.60 \%(n=2)$ of the cases.

In $13.33 \%(n=4)$ of the DRAEs, it was possible to identify flaws during the administration process, which involved the administration of a non-prescribed medication, of a higher dose than the one prescribed and leakage of chemotherapy drugs. Risk of bleeding was identified in $10.00 \%(n=3)$ of the cases, and the results of activated thromboplastin time were above 100 seconds. In $66.67 \%(n=2)$ of the cases, it was observed that the patient was using two anticoagulants concomitantly.

The medications that were most involved in DRAEs are described in Table 3. Of a total of 39 medications, it was observed that $53.85 \%(n=21)$ were HAMs. Anticoagulants were the medication class most involved in the DRAEs, with $20.50 \%(n=8)$. Both enoxaparin and warfarin were involved in DRAEs in $37.50 \%$ $(n=3)$ of the cases; and heparin, in $25.00 \%(n=2)$. In its turn, antineoplastic agents were involved in DRAEs in $12.80 \%(n=5)$ of the cases. The medications in this class associated with DRAEs were the following: cisplatin, cyclophosphamide, idarubicin and obinutuzumab.

Figure 1. Method proposed for the implementation of the active search for drug-related adverse events guided by triggers in a teaching hospital of the Sentinela Network.

Stage 1

Elaboration

of the list of

triggers

Stage 2

Elaboration of the

list of patients

Stage 3

Active search in

the ward

Stage 4

Validation of the

DRAE

Stage 5

Notification of

the DRAE

Stage 6 Typing into

the database
The team of researchers (ACFM; LTS), with previous experience with the triggers, ${ }^{11,20}$ selected the material from the Institute of Healthcare Improvement $(\mathrm{IHI})^{14}$ for the elaboration of the list to be initially used. A literature review was conducted in Pubmed and in the Virtual Health Library, using the following descriptors: "drug-related side effects and adverse reactions", "medication errors", "pharmacovigilance", "risk management" and "inpatients". The following terms outside the controlled vocabulary were used: "trigger tool" and "active search". The studies selected were those that have been conducted in Brazilian public institutions. After reading the material, a preliminary list of triggers was elaborated, which was validated by two pharmacist of the service.

As the institution does not have an electronic medical record, the research used the systems for recording laboratory tests and managing materials, including medications to search triggers. The "Reports" system allows searching for results of laboratory tests and the Material Management System (SamNet) allows searching for medications dispensed to the hospitalized patient. In this stage, the following triggers were excluded: leukocyte count $<3,000$ and platelet count $<50,000$ due to the impossibility of extracting and filtering the results per patient in the system, resulting in the final list (Table 1 ).

Support materials were elaborated for conducting the Active Search (AS) in the ward. The first contained information about the triggers, rationale for use, and associated medications (ACFM), as well as a script adapted from the method proposed by the IHI ${ }^{14}$ to search for information in the patient's medical record (LTS). Subsequently, these materials were validated by two pharmacists of the service. At the beginning of rotation, the resident pharmacists received theoretical training on the methodology proposed by the IHI and, subsequently, the practical training was supervised by the pharmacist of the service for a week or until the pharmacist considered it pertinent.

A script adapted from ${ }^{5,10}$ was developed for the assessment of the DRAEs, considering the following criteria: DRAE previously described in the literature, pharmacological plausibility of the suspected medication(s); temporality relationship between the use of the suspected medication(s) and the DRAE; exclusion of confounding variables, such as the patient's clinical condition. The team of researchers consisted of a pharmacist of the service, with a PhD and six years of experience in risk management and pharmacovigilance, in addition to publications in the area ${ }^{11,20}$ and of pharmacists from the multi-professional residency in health. All suspected cases were discussed among the pharmacists and, in case of disagreements or doubts, the case was presented to other members of the multidisciplinary team that make up the Quality Management and Health Surveillance Sector for validation through consensus.

The institution is part of ANVISA's Sentinela Network and all the DRAEs identified were notified by the pharmacist of the service, with access to Notivisa.

A database was developed in the Epi Info software, version 7.2, available in https://www.cdc.gov/epiinfo/index.html, to systematize the divers information resulting from the AS process. 
Figure 2. Work process corresponding to the active search for drug-related adverse events guided by triggers in a teaching hospital of the Sentinela Network.

"sedation/lethargy/fall", and "capillary blood glucose $<50 \mathrm{mg} / \mathrm{dL}$ " triggers were not included because it is not possible to previously identify the patients due to the unavailability of an electronic medical record system in the institution. However, the "presence of Clostridium difficile' and "digoxin levels $>2 \mathrm{ng} / \mathrm{dL}$ " triggers were not included because the institution does not conduct these tests. The following were included: amphotericin B in all its presentations and polymyxin B due to the institution's previous experience with these medications in the identification of potential DRAEs.

The pharmacist of the PVS accesses the Reports and SamNet systems daily to search for patients who have used any medication or presented any suspicious laboratory test results during the last 24 hours and manually prepares a spreadsheet for the active search (Figure 1).

The pharmacist reviews the chart searching for signs of the occurrence of DRAEs related to the trigger identified. If necessary, in this stage additional information is collected together with the health professionals, patient and caregiver. In case of identifying any suspected DRAE, the pharmacist of the PVS writes down the data in the spreadsheet for the active search (Figure 1).

In this stage, information is detailed regarding: i) characterization of the patient: gender, age, comorbidities, history of allergies; ii) suspected and concomitant medications(s): dose, dosage, diluent, infusion rate, infusion time, potential drug interactions; iii) results of laboratory tests: when pertinent, additional information regarding the results of laboratory tests is collected; iv) after collecting all the information, an assessment is made of the causal link between the potential adverse event and the suspected medication. Finally, the causality algorithm by Naranjo et al. $1981^{*}$ is applied.

After validation of the DRAE, due notification of all the cases is made to Notivisa.

After validation and notification of the DRAE cases to Notivisa, all the data referring to the AS results are typed into a database to systematize the information.

"Naranjo CA; Busto U; Sellers EM et al., 1981. ${ }^{32}$

Table 1. Characterization and positive predictive value of the triggers used for the active search of drug-related adverse events.

\begin{tabular}{lll}
\hline & & DRAEs identified by \\
Trigger $^{1}$ & Reason for its use ${ }^{1}$ & Number of times \\
& & that the trigger was $\begin{array}{l}\text { the trigger } \\
\text { present } n(\%)\end{array}$
\end{tabular}

\section{Medications}

\section{Antihistamines}

Dexchlorpheniramine

Promethazine

\section{Epinephrine}

Vitamin K

Protamine

Flumazenil

Antiemetics

Bromopride

Metoclopramide

Ondansetron

\section{Naloxone}

Loperamide

Calcium polystyrene sulfonate

Digoxin $0.25 \mathrm{mg}$ OR

Polymyxin B

Amphotericin B (all presentations)

\section{Laboratory tests}

Creatinine ( $>$ baseline value)

Serum potassium $<3 \mathrm{mg} / \mathrm{dL}$

Serum potassium $>6 \mathrm{mg} / \mathrm{dL}$

$\mathrm{INR}^{3}>6$

$\mathrm{APTT}^{4}>100 \mathrm{~s}$
Investigate the occurrence of allergic reactions to medications

Hypersensitivity to medications

Excessive anticoagulation due to warfarin

Excessive bleeding due to heparin

Excessive sedation due to benzodiazepines

Excessive toxicity due to medication use

Narcotic antagonist, it indicates opioids overdose

Diarrhea associated with medication use

Hyperkalemia associated with medication use

Verify digoxin's toxic level

Infusion reactions

$1(0.12)$

$1(0.25)$

$1(1.00)$

$8(2.00)$

Infusion reactions

Kidney failure associated with medication use Hypokalemia associated with medication use Hyperkalemia associated with medication use Excessive anticoagulation associated with coumarins Excessive anticoagulation associated with heparin

$$
-
$$

157 (39.15)

5 (1.25)

$94(23.44)$

$1(0.25)$

4 (1.00)

$3(0.75)$

$3(0.75)$

$11(2.74)$

$17(4.54)$

$52(12.97) \quad 2(0.04)$

$25(6.23) \quad 4(0.16)$

$1(0.25) \quad 1(1.00)$

$3(0.75) \quad 2(0.67)$

$8(2.00) \quad 2(0.25)$

$401(100.00) \quad 17(0.04)$

Total

401 (100.00)

${ }^{1}$ Adapted from: Rozenfeld S, Giordani F, Coelho S. 2013:10 Institute of Healthcare Improvement, 2004.11 Silva MDG, Martins MAP, Viana LG et al., $2018.21{ }^{2}$ Positive Predictive Value. ${ }^{3}$ International Normalized Ratio; ${ }^{4}$ Activated Partial Thromboplastin Time. 
Table 2. Characterization of the drug-related adverse events identified in the active search by means of s.

\begin{tabular}{|c|c|c|c|}
\hline $\begin{array}{l}\text { Drug-related } \\
\text { adverse event }\end{array}$ & $\begin{array}{l}\text { Prevalence } \\
\mathrm{N}=30 \\
\mathrm{n}(\%)\end{array}$ & Details & $\begin{array}{l}\text { Prevalence } \\
\mathrm{n}(\%)\end{array}$ \\
\hline \multirow{5}{*}{ Infusion reaction } & \multirow{5}{*}{$7(23.33)$} & Fever, desaturation, chills, tremors during the infusion of amphotericin B. Medication was suspended. & $2(28.60)$ \\
\hline & & Burning sensation in the body and intense sweating after infusion of intravenous potassium. & $2(28.60)$ \\
\hline & & Itching in the body during the infusion of tramadol. & $1(14.28)$ \\
\hline & & Chills during the infusion of obinutuzumab after increasing the infusion rate. & $1(14.28)$ \\
\hline & & Dyspnea during infusion of hyoscine. The medication was suspended. & $1(14.28)$ \\
\hline \multirow{4}{*}{$\begin{array}{l}\text { Administration } \\
\text { error }\end{array}$} & \multirow{4}{*}{$4(13.33)$} & Extravasation of cyclophosphamide during infusion. & $1(25.00)$ \\
\hline & & Mistaken administration of $10 \mathrm{IU}$ of Apidra instead of Lantus insulin. & $1(25.00)$ \\
\hline & & Administration of double dose of hyoscine to the patient. & $1(25.00)$ \\
\hline & & Administration of a double dose of ceftriaxone to the patient. & $1(25.00)$ \\
\hline \multirow{3}{*}{ Prolonged APTT ${ }^{1}$} & \multirow{3}{*}{$3(10.00)$} & $\mathrm{APTT}>100 \mathrm{~s}$ & $2(66.70)$ \\
\hline & & APTT > 200 s due to the concomitant use of heparin, clopidogrel and acetylsalicylic acid. & $1(33.30)$ \\
\hline & & Hypokalemia associated with the use of Amphotericin B & $2(50.00)$ \\
\hline \multirow[t]{2}{*}{ Hypokalemia } & \multirow[t]{2}{*}{$4(13.33)$} & Hypokalemia associated with the concomitant use of salbumatol and hydrocortisone. & $1(25.00)$ \\
\hline & & Hypokalemia associated with the concomitant use of salbumatol and terbutaline. & $1(25.00)$ \\
\hline \multirow{2}{*}{ Hepatotoxicity } & \multirow{2}{*}{$2(6.67)$} & Hepatotoxicity associated with idarubicin. & $1(50.00)$ \\
\hline & & Hepatotoxicity associated with rifampicin, isoniazid, pyrazinamide and etambutol. & $1(50.00)$ \\
\hline \multirow{2}{*}{ Nephrotoxicity } & \multirow{2}{*}{$2(6.67)$} & Acute kidney failure due to cisplatin. & $1(50.00)$ \\
\hline & & Tubulopathy due to cisplatin. & $1(50.00)$ \\
\hline Prolonged INR ${ }^{2}$ & $2(6.67)$ & INR $>5$. Patient in concomitant use of warfarin and omeprazole. & $2(100.0)$ \\
\hline Diarrhea & $1(3.33)$ & Diarrhea after the use of amoxicillin + clavulanic acid. & $1(100.0)$ \\
\hline Hyperkalemia & $1(3.33)$ & Potassium > 7.5 on the tenth day of use of sulfamethoxazole + trimethoprim The medication was suspended. & $1(100.0)$ \\
\hline Hypotension & $1(3.33)$ & Hypotension after using enalapril. There was dose reduction. & $1(100.0)$ \\
\hline Vomiting & $1(3.33)$ & Vomiting in large quantities after administration of mineral oil. & $1(100.0)$ \\
\hline Skin rash & $1(3.33)$ & The patient presented skin rash after administration of amoxicillin + clavulanic acid & $1(100.0)$ \\
\hline $\begin{array}{l}\text { Cardiopulmonary } \\
\text { arrest }\end{array}$ & $1(3.33)$ & $\begin{array}{l}\text { The patient presented cardiopulmonary arrest during infusion of Polymyxin B. The medication was } \\
\text { suspended. }\end{array}$ & 1 (100.0) \\
\hline
\end{tabular}

${ }^{1}$ Activated Partial Thromboplastin Time. ${ }^{2}$ International Normalized Ratio.

\section{Discussion}

Studies that use the DRAE research method through triggers ${ }^{7}$ in institutions that do not have information technology resources, such as electronic medical records, are scarce in the literature. However, the results in this study were close to those of others conducted in institutions with technological support, both in Brazil ${ }^{5}$ and abroad. ${ }^{19}$ Our findings can contribute to institutions that, like ours, do not have the support of an electronic medical record to implement intensive monitoring measures for DRAEs in order to assess the harms caused by drugs and to contribute with the WHO in achieving the main goal of the Third Global Patient Safety Challenge.

The frequency of DRAEs identified in our study was very close to the findings of another study conducted in a Canadian hospital, with $7 \% \cdot{ }^{19}$ Other institutions that also used triggers for the detection of DRAEs in Brazil found divergent results, with $10.7 \%{ }^{5}$ and $15.6 \% .^{10}$ Despite these differences, health institutions must use valid methods that are applicable to their reality for the detection of DRAEs, as the method of triggers. Obtaining reliable data regarding the historical series of the DRAEs is necessary for the adoption of measures to improve safety in the use of medications.

Regarding the global PPV, results differing from those found in the literature were observed. A study conducted in the same institution, specific to pediatrics, found a global PPV of $0.13 .{ }^{20}$ In hospitals of the Brazilian Southeast region, PPVs of $0.43^{5}$ and $0.08^{21}$ were observed. These differences can be partially attributed to the fact that the registration of the information necessary for safe care is not commonly found in medical records, according to the results of a study conducted in Brazil. ${ }^{22}$ In addition to that, in our study, the global PPV of the triggers may have been influenced by the low performance of the antiemetics.

In our study, when the PPVs were analyzed per trigger, promethazine showed the best performance. However, this result is not in line with the findings of a study conducted in a hospital in the Brazilian Southeast region, for which the PPV of the antihistamines was zero. ${ }^{10}$ Findings of a systematic review showed PPVs for antihistamines ranging from 0.02 to $0.30 .{ }^{18}$ The high PPV of promethazine in our study can be related to the fact that, during the study period, the trigger was found only once, and the medical records evidenced a causal relationship of the use of promethazine to alleviate symptoms of an allergic reaction associated with the use of antimicrobials. More studies are necessary to estimate the performance of promethazine in our institution.

In our study, the INR showed good performance, as observed in other studies, with results of 0.75 in a survey conducted in Brazil ${ }^{5}$ and, in the United States, PPVs of $0.50^{17}$ and $0.82^{23}$ were found. The high performance of this trigger can be explained by the fact that there is already risk of bleeding even in patients with INR $>3.5 .{ }^{24}$

Regarding the low performance of the antiemetics, the PPV of the triggers can be influenced by several factors, including the institution's prescription practices. ${ }^{5}$ In the inpatient unit where the data were collected, the prescription of antiemetics is common due to the supporting treatment of onco-hematology patients, and this can be a confusing factor regarding the low frequency of DRAEs associated with this trigger. More studies are necessary to understand the performance of this trigger in our institution. 
Table 3. Characterization of the drugs involved in drug-related adverse events identified by triggers.

\begin{tabular}{|c|c|c|c|}
\hline Class & ATC $^{1}$ code & Name & $\mathrm{n}(\%)$ \\
\hline Digestive tract and metabolism & A & & 7 (17.9) \\
\hline Medications for the treatment of gastrointestinal disorders & A02BC01. & omeprazole & $3(7.7)$ \\
\hline Antiemetics and antinauseants & A04AD01. & hyoscine & $2(5.1)$ \\
\hline Medications for constipation & A06AG06. & mineral oil & $1(2.6)$ \\
\hline Medications used in diabetes & A10AB06. & insulin & $1(2.6)$ \\
\hline \multirow[t]{3}{*}{ Blood and hematopoietic organs } & G & & $12(30.8)$ \\
\hline & B01AA03. & warfarin & $3(7.7)$ \\
\hline & B01AB01. & heparin & $2(5.1)$ \\
\hline \multirow[t]{3}{*}{ Antithrombotic agents } & B01AB05. & enoxaparin & $3(7.7)$ \\
\hline & B01AC04. & clopidogrel & $1(2.6)$ \\
\hline & B01AC06. & acetylsalicylic acid & $1(2.6)$ \\
\hline Blood substitutes and perfusion solutions & B05XA01. & potassium chloride & $2(5.1)$ \\
\hline Cardiovascular system & C & & $2(5.1)$ \\
\hline Diuretics & C03CA01. & furosemide & $1(2.6)$ \\
\hline Agents acting on the renin-angiotensin system & CO9AA02. & enalapril & $1(2.6)$ \\
\hline Hormonal preparations for systemic use excluding sex hormones and insulin & H & & $1(2.6)$ \\
\hline Corticosteroids for systemic use & H02AB09. & hydrocortisone & $1(2.6)$ \\
\hline Anti-infectives for systemic use & J & & $8(20.5)$ \\
\hline \multirow{4}{*}{ Antibacterial drugs for systemic use } & J01CR02. & amoxicillin + clavulanic acid & $1(2.6)$ \\
\hline & J01EE01. & sulfamethoxazole + trimethropim & $1(2.6)$ \\
\hline & J01DD04. & ceftriaxone & $1(2.6)$ \\
\hline & Ј01XB02. & polymyxin B & $1(2.6)$ \\
\hline Antifungals for systemic use & J02AA01. & amphotericin B & $3(7.7)$ \\
\hline Antimycobacterials & J04AM06. & $\begin{array}{l}\text { rifampicin + pyrazinamide +etambutol+ } \\
\text { isoniazid }\end{array}$ & $1(2.6)$ \\
\hline Antineoplastic and immunomodulating agents & $\mathbf{L}$ & & $5(12.8)$ \\
\hline \multirow{4}{*}{ Antineoplastic agents } & L01AA01. & cyclophosphamide & $1(2.6)$ \\
\hline & L01DB06. & idarubicin & $1(2.6)$ \\
\hline & L01XA01. & cisplatin & $2(5.1)$ \\
\hline & L01XC15. & obinutuzumab & $1(2.6)$ \\
\hline Nervous system & $\mathbf{N}$ & & $1(2.6)$ \\
\hline Analgesics & N02AX02. & tramadol & $1(2.6)$ \\
\hline Respiratory system & $\mathbf{F}$ & & $3(7.7)$ \\
\hline \multirow{2}{*}{ Medications for obstructive diseases of the airways } & R03CCO2. & salbutamol & $2(5.1)$ \\
\hline & R03CC03. & terbutaline & $1(2.6)$ \\
\hline
\end{tabular}

${ }^{1}$ Anatomical Therapeutic Chemical Classification.

Regarding the type of DRAE identified, the finding in our study is in line with that of a Brazilian study on PV activities carried out by hospital pharmacists, where $55.4 \%$ of these were related to the investigation of ADRs. ${ }^{25} \mathrm{~A}$ higher frequency of ADRs observed in our study can be partially attributed to the fact that, considering the effects of ADRs resulting from the use of the medication in usual doses, ${ }^{15}$ the recording of this information in the patient's medical record can be more easily identified than records resulting from failures during assistance.

In our study, we observed that more than $50 \%$ of the DRAEs were related to infusion reactions. A high frequency of reactions related to the infusion of medications was also observed in a study conducted at a pediatric teaching hospital in Brazil. ${ }^{26}$ In our study, amphotericin B was associated with infusion reactions, results in line with those of another study conducted in a university hospital in the Brazilian Southregion. ${ }^{27}$ The most frequent reactions observed in this study were related to the infusion: vomiting, nausea, phlebitis, hyperthermia and cephalea. ${ }^{27}$ Considering amphotericin B in all its presentations as a $\mathrm{HAM}^{2}{ }^{2}$ the pharmacist must identify risk situations and implement measures for the prevention of DRAEs.
The infusion of solutions containing potassium was associated with infusion reactions in our present. Even diluted, potassium can cause harms to the patient, and infusion-related reactions are common, as evidenced by other studies. ${ }^{28,29}$ Potassium for peripheral infusion must be preferably diluted at a rate $>40 \mathrm{mEq} / \mathrm{L}$ and the infusion rate should not exceed $10 \mathrm{mEq} /$ hour. ${ }^{30}$ Although potassium was prescribed in the appropriate dilution range and infusion speed considered safe, in our study, it was not possible to retrieve information regarding compliance with the prescription at the time of administration.

Regarding the types of medications most involved in DRAEs in our study, we observed that more than $50 \%$ were high-alert drugs. In a study conducted with more than 70,000 incident reports from hospitals in the United Kingdom, it was found that nearly $24.0 \%$ of the events were related to the use of HAMs. ${ }^{31}$ Safe management of HAMs is one of the priority areas listed by the WHO to improve safety in the use of medications. ${ }^{2}$ Considering the impact of the DRAEs involving HAMs, especially in hospitals, ${ }^{31}$ health institutions should seek methods to actively detect DRAEs, since most of them are underreported. ${ }^{4}$ The assessment of these incidents can assist in the identification of risk situations to propose improvement actions with a view to preventing harms to the patient. 
Our study presented some limitations, and the main one was the low quality of the records of incidents in the patients' medical charts, as evidenced by another Brazilian study.22 The absence of these records can result in underestimated DRAE data, since AS by triggers assumes that the information must be clear at the time of the medical record review. However, our results are valid since, even without the support of an electronic medical record, it was possible to identify and notify DRAEs that would otherwise not be captured. Additional studies are necessary to improve the selection of the triggers with best performance for the AS of DRAEs in our institution.

\section{Conclusion}

It was found that the implementation of an active search service for DRAEs in an institution that does not have the support of an electronic medical record system is feasible to be performed. High frequency of DRAEs was evidenced, as well as that the active search guided by triggers allows detecting events that could not be otherwise identified. The results evidence that, even in institutions that do not have the support of electronic medical records, it is possible to implement methods to asses harms related to the use of medications, in addition to enabling the adoption of measures for the management of DRAEs directed at each institution.

\section{Funding sources}

The authors declare that the research did not receive funding for its conduction.

\section{Collaborators}

ACM, LTS and WSN participated in all the study phases (conception of the project and data analysis and interpretation; writing of the article and relevant critical review of the intellectual content; final approval of the version to be published; responsibility for all the information included in the paper, ensuring accuracy and integrity of any of its parts); MPP, RGA and TMF participated in the relevant critical review of the intellectual content and in the final approval of the version to be published.

\section{Acknowledgments}

The authors would like to thank the Quality Management and Health Surveillance Sector of the Clinical Hospital-Federal University of Goiás/EBSERH for the permission granted to collect data for this study.

\section{Conflict of interest statement}

The authors declare that there are no conflicts of interest regarding this article.

\section{References}

1. International Pharmaceutical Federation. Patient safety Pharmacists ' role in "Medication Without Harm", 2020.
2. Sheikh A, Dhingra-Kumar N, Kelley E, et al. The third global patient safety challenge: Tackling medication-related harm. Bull World Health Organ. 2017;95(8):545-6. DOI: 10.2471/ BLT.17.198002.

3. Cano FG, Rozenfeld S. Adverse drug events in hospitals: a systematic review. Cad Saude Publica 25 Sup 3:S360-S372, 2009. DOI: 10.1590/S0102-311X2009001500003.

4. Hazell L, Shakir SAW. Under-Reporting of Adverse A Systematic Review. Drug Saf. 2006;29(5):385-96. DOI: 10.2165/00002018-200629050-00003.

5. Varallo FR, Dagli-Hernandez C, Pagotto C, et al. Confounding Variables and the Performance of Triggers in Detecting Unreported Adverse Drug Reactions. Clin Ther. abril de 2017;39(4):686-96. DOI: 10.1016/j.clinthera.2016.11.005.

6. Varallo FR, Guimarães SDOP, Abjaude SAR, et al. Causes for the underreporting of adverse drug events by health professionals: a systematic review. Rev da Esc Enferm da USP [Internet]. 2014;48(4):739-47.

7. Resar RK, Rozich JD, Classen D. Methodology and rationale for the measurement of harm with trigger tools. Qual Saf Heal Care. 2003;12(Suppl II):39-45. DOI: 10.1136/qhc.12.suppl_2. ii39.

8. Ogata H, Motta FA, Ricieri MC. Naloxona como gatilho para identificar eventos adversos com opióides em unidades de terapia intensiva pediátricas. Rev Bras Farmácia Hosp e Serviços Saúde. 2019;10(2):1-5. DOI: 10.30968/ rbfhss.2019.102.0411.

9. Nóbrega LC, Sousa LB, Gomes VP, et al. Medicamentos rastreadores na identificação de reações adversas em um hospital. Rev Bras Farmácia Hosp e Serviços Saúde. 2016;7(3):42-5.

10. Rozenfeld S, Giordani F, Coelho S. Adverse drug events in hospital: Pilot study with trigger tool. Rev Saude Publica. 2013;47(6):1102-11. DOI: 10.1590/S00348910.2013047004735.

11. Teles L, Modesto ACF, Martins RR, et al. Characterization of adverse drug events identified by trigger in Brazilian pediatric inpatients. J Pediatr [Internet]. 2020;96(3):393-401.

12. Classen DC, Lloyd RC, Provost PL, et al. Development and Evaluation of the Institute for Healthcare Improvement Global Trigger Tool. J Patient Saf. 2008;4(3):169-77.

13. Classen BDC, Resar R, Griffin F, et al. 'Global Trigger Tool' shows that adverse events in hospitals may be ten times greater than previously measured. Health Aff. 2011;30(4):581-9. DOI: 10.1377/hlthaff.2011.0190

14. Institute of Healthcare Improvement. Trigger Tool for measuring adverse drug events. 2004.

15. Varallo FR, Mastroianni PC. Métodos em farmacovigilância. In: Varallo FR, Mastroianni PC, organizadores. Farmacovigilância para promoção do uso correto de medicamentos. 1a ed Porto Alegre: Artmed; 2013. p. 184.

16. World Health Organization. Guidelines for ATC classification and DDD assignment 2015. Vol. 1, WHO Collaborating Centre for Drug Statistics Methodology, Guidelines for ATC classification and DDD assignment 2015. 2015. 
17. Instituto para Práticas Seguras no Uso de Medicamentos. Medicamentos Potencialmente Perigosos de Uso Hospitalar - Lista Atualizada 2019. Vol. 8. 2019.

18. Handler SM, Altman RL, Pereira S, et al. A Systematic Review of the Performance Characteristics of Clinical Event Monitor Signals Used to Detect Adverse Drug Events in the Hospital Setting. J Am Med Informatics Assoc. 2007;14(4):451-8. DOI: 10.1197/jamia.m2369.

19. Lau I, Kirkwood A. Measuring adverse drug events on hospital medicine units with the Institute for Healthcare Improvement trigger tool: A chart review. Can J Hosp Pharm. 2014;67(6):423-8. DOI: 10.4212/cjhp.v67i6.1404.

20. Teles L, Modesto ACF, Martins RR, et al. The Brazilian Portuguese version of the Pediatric Trigger Toolkit is applicable to measure the occurrence of adverse drug events in Brazilian pediatric inpatients. J Pediatr (Rio J) [Internet]. 2019;95(1):61-8

21. Silva MDG, Martins MAP, Viana LG, et al. Evaluation of accuracy of $\mathrm{IHI}$ Trigger Tool in identifying adverse drug events a prospective observational study. $\mathrm{Br} J$ Clin Pharmacol. 2018;84:2252-9. DOI: 10.1111/bcp.13665.

22. Pavão ALB, Andrade D, Mendes W, et al. Estudo de incidência de eventos adversos hospitalares, Rio de Janeiro, Brasil avaliação da qualidade do prontuário do paciente. Rev Bras Epidemiol. 2011;14(4):651-61.

23. Buckley MS, Rasmussen JR, Bikin DS, et al. Trigger alerts associated with laboratory abnormalities on identifying potentially preventable adverse drug events in the intensive care unit and general ward. Ther Adv Drug Saf. 2018;9(4):207-217. DOI: 10.1177/2042098618760995.

24. Lavítola PDL, Spina GS, Sampaio RO, et al. Bleeding during Oral Anticoagulant Therapy: Warning Against a Greater Hazard. Arq Bras Cardiol. 2009;93(2):163-7. DOI: 10.1590/ s0066-782x2009000800017.

25. Henrique $\mathrm{P}$, Andrade $\mathrm{S}$, Carvalho $\mathrm{A}$, et al. Challenges to the consolidation of pharmacovigilance practices in Brazil : limitations of the hospital pharmacist. Ther Adv Chronic Dis. 2020;11:1-11. DOI: 10.1177/2042098620933748.

26. Yamamoto MS, Peterlini MAS, Bohomol E. Notificação espontânea de erros de medicação em hospital universitário pediátrico. Acta Paul Enferm. 2011;24(6):766-71. DOI: 10.1590/S0103-21002011000600006.

27. Loução AS, Jacomini D, Moroni JG, et al. Reações Adversas a Anfotericina B em adultos- Mineração de Dados. Rev Bras Farmácia Hosp e Serviços Saúde. 2018;9(1):1-6.

28. Lyons I, Furniss D, Blandford A, et al. Errors and discrepancies in the administration of intravenous infusions: a mixed methods multihospital observational study. BMJ Qual Saf. novembro de 2018;27(11):892-901. DOI: 10.1136/bmjqs-2017007476.

29. Barras M, Moore D, Pocock D, et al. Reducing the risk of harm from intravenous potassium: a multi-factorial approach in the haematology setting. J Oncol Pharm Pract. outubro de 2014;20(5):323-31. DOI: 10.1177/1078155213504443.

30. Nakatani K, Nakagami-Yamaguchi E, Tomita S, et al. Improving the safety of high- concentration potassium chloride injec- tion. BMJ Open Qual. 2019;8:1-9.

31. Härkänen M, Paananen J, Murrells T, et al. Identifying risks areas related to medication administrations - text mining analysis using free-text descriptions of incident reports. BMC Health Serv Res. 2019;9:1-9. DOI: 10.1186/s12913-0194597-9.

32. Naranjo, CA. Busto, U, Sellers EM., et al. A method for estimating the probability of adverse drug reactions. Clinical Pharmacology Therapy. 1981; 30(2)30; 239-245. DOI: 10.1038/ clpt.1981.154. 